\title{
ELECTROCHEMICAL, STRUCTURAL AND MAGNETIC STUDY OF Li-RICH CATHODE MATERIALS FOR LITHIUM-ION BATTERY
}

\author{
1Elena MAKHONINA, 'Lidia PECHEN, 'yacheslav VOLKOV, ${ }^{2,3}$ Alexander RUMYANTSEV, \\ ${ }^{2,3}$ Yury KOSHTYAL, ${ }^{1}$ Yury POLITOV, ${ }^{1}$ Vladislav PERVOV, ${ }^{1}$ Igor EREMENKO \\ ${ }^{1}$ Kurnakov Institute of General and Inorganic Chemistry of RAS, Moscow, Russian Federation, \\ elenamakhonina@mail.ru, lidia.s.maslennikova@gmail.com, svolkov77@gmail.com \\ ${ }^{2}$ loffe Institute, Saint-Petersburg, Russian Federation, \\ rumyantsev.amr@gmail.com \\ ${ }_{3}^{3}$ Peter the Great St.Petersburg Polytechnic University, Saint-Petersburg, Russian Federation, \\ yury.koshtyal@gmail.com
}

https://doi.org/10.37904/nanocon.2019.8621

\begin{abstract}
Li-rich oxides of different phase compositions $\mathrm{xLi}_{2} \mathrm{MnO}_{3} \cdot(1-\mathrm{x}) \mathrm{LiMO}_{2}$ are synthesized by coprecipitation of mixed transition metal carbonates followed by solid-state reaction with lithium hydroxide. X-ray powder diffraction, scanning electron microscopy, and magnetic studies are used to characterize the pristine structure of the oxides with different compositions. The materials are tested as positive electrode in lithium half-cells. Galvanostatic charge-discharge measurements are performed at different current densities. The lithium-ion diffusion coefficients $\left(\mathrm{D}_{\mathrm{Li}+}\right)$ are estimated from the cyclic voltammetry experiments and found to reach maximum values for composition at $\mathrm{x}=0.35$ having the best electrochemical characteristics.
\end{abstract}

Keywords: Lithium-rich cathodes, electrochemical properties, lithium-ion diffusion, magnetic measurements

\section{INTRODUCTION}

Over-lithiated layered manganese nickel cobalt oxides $\mathrm{Li}_{1+y} \mathrm{M}_{1-\mathrm{y}} \mathrm{O}_{2}(\mathrm{M}=\mathrm{Mn}, \mathrm{Ni}, \mathrm{Co})$ termed also as $\mathrm{Li}$-rich oxides attract much attention as materials for the next generation of high energy density Li-ion batteries [1-3]. The oxides can be written in another notation as $\mathrm{xLi}_{2} \mathrm{MnO}_{3} \cdot(1-\mathrm{x}) \mathrm{LiMO}_{2}$ and can be considered to be either a nanocomposite of monoclinic $\mathrm{Li}_{2} \mathrm{MnO}_{3}$ and trigonal $\mathrm{LiMO}_{2}$ phases or a solid solution between these phases. $\mathrm{Li}_{2} \mathrm{MnO}_{3}$ was initially considered as inactive for lithium insertion and extraction between $2.0 \mathrm{~V}$ and $4.4 \mathrm{~V}$; however electrochemical oxidation at a higher voltage [4] has shown that $\mathrm{Li}_{2} \mathrm{MnO}_{3}$ after this electrochemical activation demonstrates electrochemical performances better than those of $\mathrm{LiMnO}_{2}$. The activation is ascribed to partial Li+ extraction accompanied by oxygen loss from the lattice and formation of a composite structure built up of $\mathrm{Li}_{2} \mathrm{MnO}_{3}$ and $\mathrm{LiMnO}_{2}$. In the working voltage range of $2 \mathrm{~V}-4.4 \mathrm{~V}, \mathrm{Li}_{2} \mathrm{MnO}_{3}$ is supposed to act as a stabilizer of the structure [5]. Li-rich $\mathrm{Mn}$-rich $x \mathrm{Li}_{2} \mathrm{MnO}_{3} \cdot(1-x) \mathrm{LiMO}_{2}$ oxides (LMR) being electrochemically activated can show capacities exceeding $270 \mathrm{mAh} / \mathrm{g}$ or more in the first activation cycles. A high capacity of these materials is explained as due to cumulative cationic $\mathrm{Mn}^{\mathrm{n}+} \leftrightarrow \mathrm{M}^{(\mathrm{n}+1)+}$ and anionic $2 \mathrm{O}^{2-} \leftrightarrow\left(\mathrm{O}_{2}\right)^{\mathrm{n}-}$ reversible redox processes [6-8]. The activation is accompanied by structural reorganization of these oxides. Therefore, an important role plays the initial structure of the oxides. A two-phase model of Li-rich oxides $x \mathrm{Li}_{2} \mathrm{MnO}_{3} \cdot(1-$ $x) \mathrm{LiMO}_{2}$ was first proposed by Thackeray et al. [1] and the $\mathrm{Li}\left(\mathrm{Li}_{\mathrm{x}} \mathrm{M}_{1-\mathrm{x}}\right) \mathrm{O}_{2}$ model based on a solid solution with a homogeneous long-range order was proposed by Dahn et al. [9]. Both models are widely discussed in the literature, but the optimal model of the original structure is still a matter of debate. There is currently no complete understanding of the relationship between the microstructure of the material and its electrochemical characteristics [10]. Another debate issue is the influence of the material composition on the electrochemical behavior of the complex oxides. The aim of this research is to investigate the impact of pristine structure and composition of Li-rich oxides of different compositions $x \mathrm{Li}_{2} \mathrm{MnO}_{3} \cdot(1-x) \mathrm{LiM}_{1 / 3} \mathrm{Ni}_{1 / 3} \mathrm{Co}_{1 / 3} \mathrm{O}_{2}$ on their electrochemical and magnetic characteristics. 


\section{EXPERIMENTAL}

\subsection{Synthesis procedures}

Li-rich Mn-rich oxides of the compositions $0.5 \mathrm{Li}_{2} \mathrm{MnO}_{3} \cdot 0.5 \mathrm{LiMO}_{2}(\mathrm{LMR} 50), 0.35 \mathrm{Li}_{2} \mathrm{MnO}_{3} \cdot 0.65 \mathrm{LiMO}_{2}(\mathrm{LMR} 35)$, and $0.2 \mathrm{Li}_{2} \mathrm{MnO}_{3} \cdot 0.8 \mathrm{LiMO}_{2}$ (LMR20), where $\mathrm{M}=\mathrm{Mn}_{1 / 3} \mathrm{Ni}_{1 / 3} \mathrm{Co}_{1 / 3}(\mathrm{MNC})$, were synthesized by coprecipitation of appropriate carbonate precursors $\mathrm{MCO}_{3}$ followed by solid-state reactions with $\mathrm{LiOH} \cdot \mathrm{H}_{2} \mathrm{O}$. The starting reagents were manganese nitrate tetrahydrate (98\%, Alfa Aesar), nickel nitrate hexahydrate $(99.9 \%, A B C R)$, cobalt nitrate hexahydrate ( $99 \%$ Acros Organics), sodium carbonate anhydrous ( $\geq 99 \%$, Chimmed), ammonium hydroxide (special purity grade, Chimmed), and lithium hydroxide monohydrate ( $\geq 99 \%$, Sigma-Aldrich). The carbonate precursors were washed with deionized water and dried at $110^{\circ} \mathrm{C}$ in an argon flow. The mixtures of a precursor with an appropriate amount of $\mathrm{LiOH} \cdot \mathrm{H}_{2} \mathrm{O}$ (with a $3 \mathrm{wt} \%$ excess of lithium hydroxide) were annealed in air at $480^{\circ} \mathrm{C}(6 \mathrm{~h})$ and $900{ }^{\circ} \mathrm{C}(12 \mathrm{~h})$. The synthesis procedure is described in details elsewhere [11].

\subsection{Material characterization}

Powder X-ray diffraction (XRD) patterns were recorded at room temperature with a Bruker D8 Advance Vario (Cu Ka1 radiation) equipped with a Ge monochromator and position-sensitive detector LynxEye with rotating sample stage. The data were collected in the $\Theta / 2 \Theta$ scan mode in the $2 \Theta$ range of $5^{\circ}-80^{\circ}$ at a scan step of $0.02^{\circ}$. The data were collected with the use of the Bruker DIFFRACplus program package, the analysis was performed with the EVA and TOPAS softwares.

Element contents in materials under study were determined by the inductively coupled plasma massspectrometry (ICP-MS) with an Agilent Technologies Agilent 7500ce ICP-mass spectrometer. The morphology and microstructure of the samples were studied by scanning electron microscopy (SEM) using a NVision-40 (Carl Zeiss) microscope. Particle size analysis was performed with the use of a laser particle sizer Analysette 22 (Fritsch). We used the Fraunhofer model for data analysis.

The magnetic properties of the samples were studied using a Quantum Design Physical Properties Measurement System (PPMS-9) at temperatures from 4 to $300 \mathrm{~K}$ in a static field of $100 \mathrm{Oe}(7960 \mathrm{~A} / \mathrm{m})$. The sample was cooled in the absence of a magnetic field to liquid helium temperature, and then a small measuring field of $7960 \mathrm{~A} / \mathrm{m}$ (100 Oe) was applied, the temperature was slowly raised, and the magnetization was measured (zero field cooling (ZFC)). Magnetization isotherms were obtained at magnetic field strengths of up to $H=4.78 \times 10^{6} \mathrm{~A} / \mathrm{m}(60 \mathrm{kOe})$. The spin freezing temperature was evaluated from the maximum in the temperature dependence of the initial magnetization of the zero field-cooled samples.

\subsection{Electrochemical testing}

The electrochemical tests were carried out in CR2032 coin-type cells at $25^{\circ} \mathrm{C}$. The cathodes were prepared by mixing the active material, polyvinylidene fluoride, and Timcal Super $\mathrm{C} 65$ carbon black at 92:3:2 mass ratios with $\mathrm{N}$-methyl-2-pyrrolidone as the solvent. The slurry was pasted onto aluminum foil and dried at $110{ }^{\circ} \mathrm{C}$ in air. Then, the electrodes were cut out of the foil and dried under vacuum at $90{ }^{\circ} \mathrm{C}$. Celgard 2325 membranes (2 layers) were used as a separator, TC-E918 (Tinci) as an electrolyte, and metallic lithium as anode electrodes. Active material loadings were in a range of $8-12 \mathrm{mg} \mathrm{cm}^{-2}$. The samples were tested using a Neware CT3008W-5V10mA battery cycler. Before the cycling tests, each sample was subjected to electrochemical activation including consecutive double cycles in the ranges of 2.5-4.2, 2.5-4.4, and 2.5-4.8 V. Cyclic voltammetry (CVA) tests were carried out with the use of Metrohm Autolab Potentiostat-Galvanostat PGSTAT302N over 2.5-4.8 V at a scan rate from 0.05 to $0.4 \mathrm{mV} / \mathrm{s}$. 


\section{RESULTS AND DISCUSSION}

The chemical compositions of the samples under study determined by ICP-MS analysis were found to be very close to target compositions. All the samples consist of agglomerates with narrow size distribution. The agglomerate and primary particle sizes are close to each other for all the samples (Figure 1).
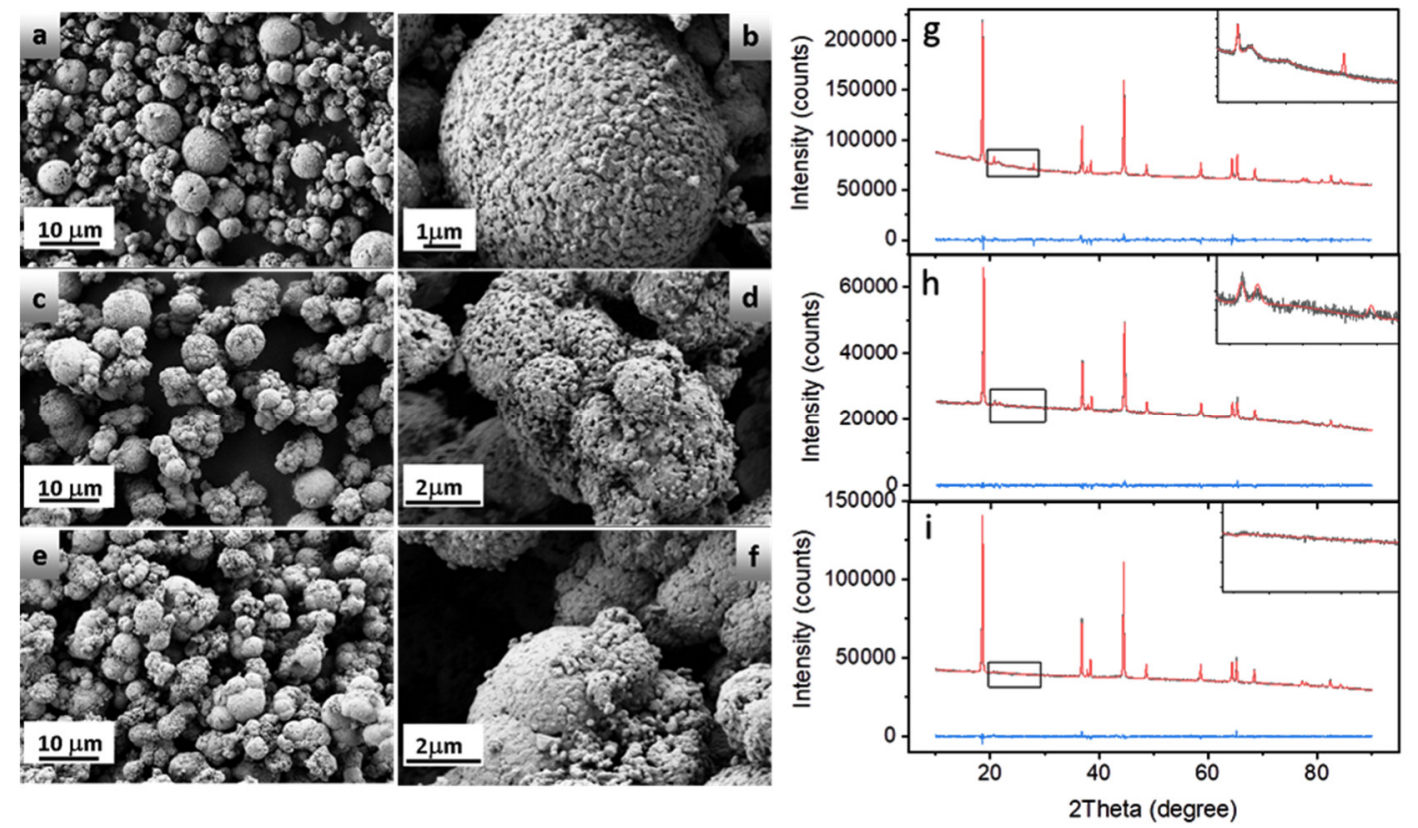

Figure 1 SEM images of samples ( $a, b)$ LMR50, (c, d) LMR35, and (e, f) LMR20; and Rietveld refinement results of the X-ray diffraction patterns of (g) LMR50, (h) LMR35, and (i) LMR20: experimental data are black lines; the calculated patterns are red solid lines; blue lines at the bottom show the difference between them.

The areas indicated by squares at $2 \Theta=19^{\circ}-28^{\circ}$ are enlarged in the inserts.

In Figure 1, we show also the results of the Rietveld refinement of the XRD data for the samples under study. The X-ray powder diffraction patterns of the samples were interpreted on the basis of the model of two structurally integrated phases: a trigonal phase, which is isostructural to $\mathrm{LiNiO}_{2}$ (the $R 3-m$ space group), and a monoclinic phase, which is isostructural to $\mathrm{Li}_{2} \mathrm{MnO}_{3}$ (the $\mathrm{C} 2 / \mathrm{m}$ space group). The quantitative phase analysis could not be carried out because of overlapping peaks of the trigonal and monoclinic phases. The most intensive peaks of the monoclinic phase, which do not coincide with peaks of the trigonal phase, have substantial anisotropic broadening (see Figure 1, insets), which cannot be simulated within the Rietveld method. This broadening is due to various degrees of disorder associated mostly with stacking faults along the $c$ monoclinic direction and made of irregular rotational twins for ordered $\mathrm{Li}_{1 / 3} \mathrm{Mn}_{2 / 3}$ sheets between the oxygen layers [12] which cannot be simulated within the Rietveld method. The unit cell parameters were refined for the trigonal phases. The a parameters were 2.85177(3), 2.85534(5), and 2.85839(3) $\AA$; and the $c$ parameters were 14.2371(3), 14.2531(6), and 14.2453(3) $\AA$ for LMR50, LMR35, and LMR20, respectively. The $c$ parameter changed non-monotonously in this row. We have evaluated the fraction of the monoclinic phase as about 40 and $20 \%$ for samples LMR50 and LMR35. Reflections of monoclinic phase are virtually not observed for LMR20.

Figure 2A demonstrates the cycling performance of the samples in the range of 2.5-4.8 V. In the same figure we show also the results of cyclic voltammetry of the oxides. Electrochemical measurements show both the best cyclability and rate capability of sample LMR35. In spite of a greater voltage fade for LMR35, its discharge 
capacity and energy exceed those for the oxides of other compositions. We have evaluated the Lithium-ion diffusion coefficients $\left(D_{\llcorner\mathrm{i}}\right)$ for these oxides from our data of cyclic voltammetry.
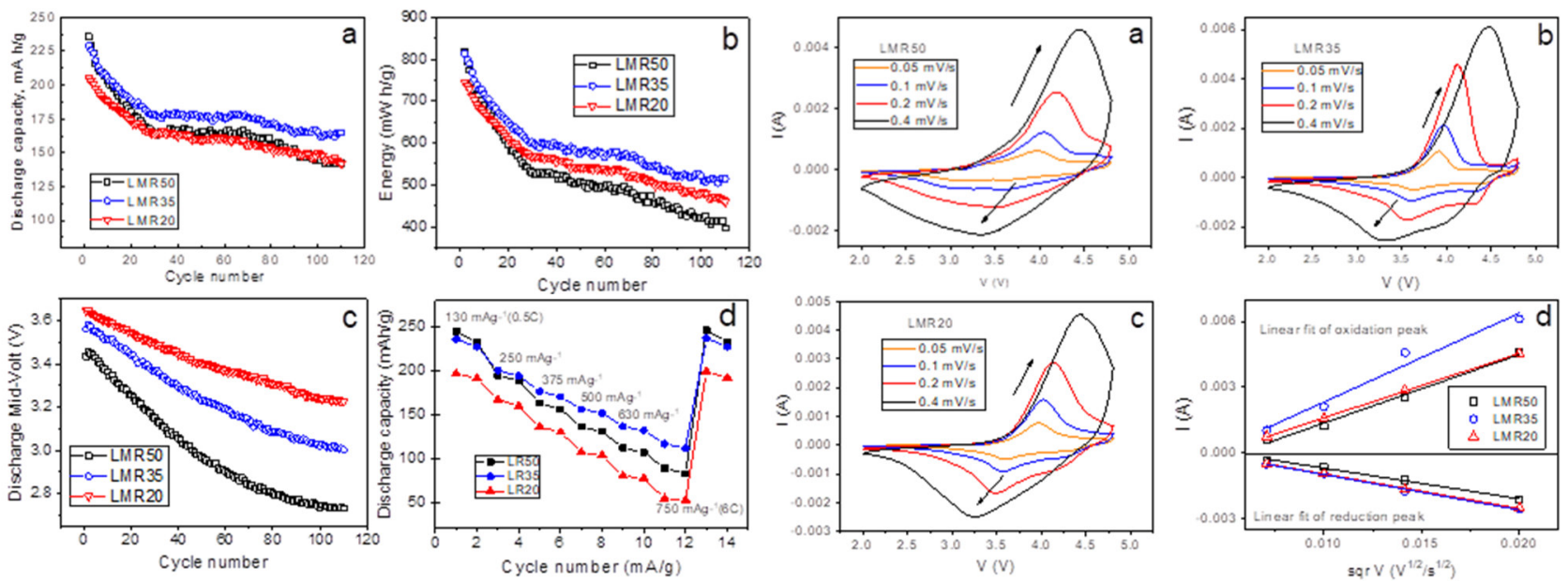

A

B

Figure 2 (A) Discharge characteristics in the voltage range of 2.5-4.8 V: (a) capacity, (b) energy, (c) midvoltage, and (d) rate capability; (B) (a-c) I-V curves for LMR50, LMR35, and LMR20, respectively; (d) linear fit of the peak currents versus the square root of scanning rates for the samples.

The lithium-ion diffusion coefficient was calculated based on the I-V curves with different scan rates in the voltage range of 2.5-4.8 $\mathrm{V}$ (Figure 2B). In diffusion controlled process, the peak current is proportional to the square root of the scanning rates, which is in line with the Randles-Ševcik equation [13]:

$$
i_{p}=0.4463 n F A C\left(\frac{n F v D}{R T}\right)^{1 / 2}
$$

where $i_{p}$ is the peak current, $n$ is the number of the electrons transferred, $C$ is the concentration of $\mathrm{Li}+, A$ is the surface area of the electrode, $v$ is the scan rate, $F$ stands for the Faraday constant, and $D$ is the diffusion coefficient of lithium ions.

Figure $\mathbf{2 B}(\mathbf{d})$ shows the dependences of the current at the anodic and cathodic maxima on the root of the potential scan rate. The linear approximation gives good results for the anodic and cathodic current dependences for all the samples, except for the anodic current dependence found for LMR35. Nevertheless, Adjusted R-Squared is a rather high value $(0.958)$ in this case too, and we can formally consider that all these dependences satisfy the Randles-Ševcik equation. The diffusion coefficients of deintercalation $O-D_{\llcorner i}$ and intercalation $R-D_{\llcorner\mathrm{Li}}$ are calculated from the oxidation and reduction peaks, respectively, and the data are compiled in Table 1.

Table 1 The calculated diffusion coefficients of $\mathrm{Li}+$ for deintercalation and intercalation processes

\begin{tabular}{|c|c|c|}
\hline Sample & $\boldsymbol{O}-\boldsymbol{D}_{L i}\left(\mathbf{c m}^{2} \mathbf{s}^{-1}\right)$ & $R-D_{L i}\left(\mathbf{c m}^{2} \mathbf{s}^{-1}\right)$ \\
\hline LMR50 & $8.10^{*} 10^{-11}$ & $1.72^{*} 10^{-11}$ \\
\hline LMR35 & $1.39^{*} 10^{-10}$ & $2.43^{*} 10^{-11}$ \\
\hline LMR20 & $7.42^{*} 10^{-11}$ & $2.18^{*} 10^{-11}$ \\
\hline
\end{tabular}


As is seen from these data, oxide LMR35 has the greater diffusion coefficients for both deintercalation and intercalation processes. These findings correlate with its electrochemical characteristics.

Since magnetic properties are sensitive to the cation distribution [14], magnetic measurements were also used to characterize the samples. The magnetic parameters of the oxides are summarized in Table 2.

Table 2 Magnetic parameters of the samples

\begin{tabular}{|c|c|c|c|c|c|}
\hline Sample & $\mathbf{C}(\mathbf{e m u K} / \mathrm{mol})$ & $\boldsymbol{\Theta}(\mathbf{K})$ & $\boldsymbol{\mu}_{\exp }(\boldsymbol{\mu B})$ & $\boldsymbol{\mu}_{\text {theory }}(\boldsymbol{\mu B})$ & $\mathbf{T}_{\mathbf{N}}(\mathbf{K})$ \\
\hline LMR50 & 1.53 & 46.87 & 3.264 & 3.400 & 70.0 \\
\hline LMR35 & 1.32 & 50.77 & 2.997 & 3.057 & 43.2 \\
\hline LMR20 & 1.23 & 61.12 & 2.854 & 2.916 & 22.6 \\
\hline
\end{tabular}

The Curie constants (C) and Curie-Weiss temperatures $(\Theta)$ are calculated by fitting the temperature dependence of inverse dc magnetic susceptibility at high temperature using the Curie-Weiss law (Figure 3). The negative Curie-Weiss temperatures indicate the dominant antiferromagnetic interaction in these compounds. The experimental values of the magnetic moments derived from the Curie constants agree well with the theoretical magnetic moments calculated assuming the existence of $\mathrm{Ni2}+, \mathrm{Mn} 4+$ and $\mathrm{Co} 3+$ ions.
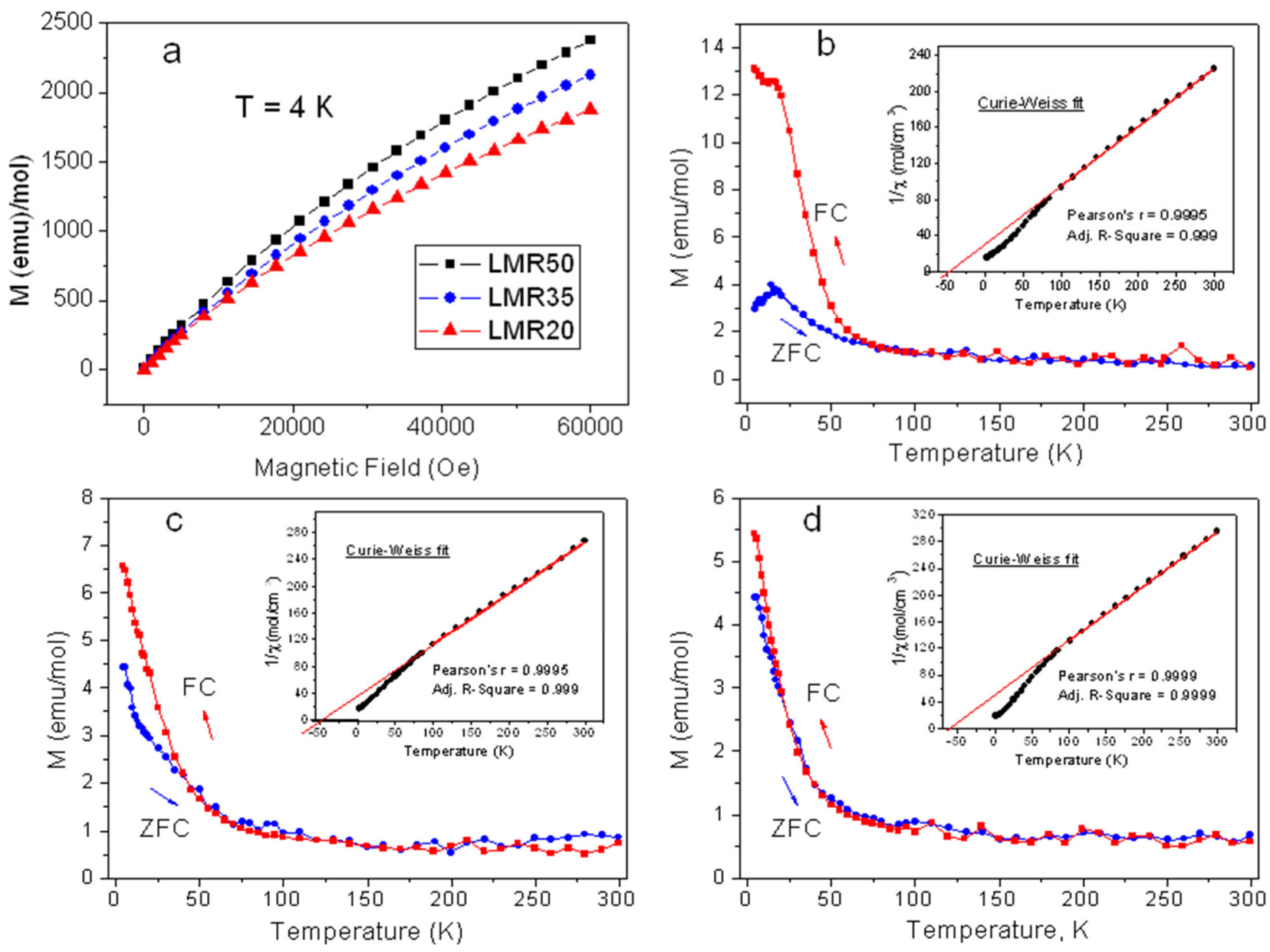

Figure 3 Molar magnetization vs. (a) field $\mathrm{H}$ and (b-d) temperature at $\mathrm{H}=100$ Oe for LMR50, LMR35, and LMR20, respectively. The insets show the Curie-Weiss law fitting for inverse magnetic susceptibility $1 / X$. 
Figure 3 shows different magnetic behavior of the samples. The FC and ZFC curves bifurcate at the Néel temperature $\left(T_{N}\right)$ indicating a transition from paramagnetic to antiferromagnetic ordering in the lattice. $T_{N}$ gradually decreases when going from LMR50 to LMR20. The same tendency is observed for the dependences of molar magnetization on the magnetic field (Figure 3a). This behavior agrees with the $\mathrm{Li}_{2} \mathrm{MnO}_{3}$ content in the samples. The magnetic transition is not expected in the case of layered stoichiometric $\mathrm{LiMO}_{2}$ compounds of R-3m space group, where lithium ions occupy only the Li sites and TM ions occupy the TM sites [15]. $\mathrm{T}_{\mathrm{N}}$ temperature for $\mathrm{Li}_{2} \mathrm{MnO}_{3}$ is equal to $50 \mathrm{~K}$ [16]. If we consider the monoclinic phase as the only cause of this transition, the transition temperature is supposed to be the same for all the samples. However in our case, a close value was obtained only for LMR35. $\mathrm{T}_{\mathrm{N}}$ values can differ from $\mathrm{T}_{\mathrm{N}}$ of $\mathrm{Li}_{2} \mathrm{MnO}_{3}$ due to some structural defects (vacancies) or the presence of $\mathrm{Mn}$ or $\mathrm{Ni}$ ions in the lithium layer.

\section{CONCLUSION}

Among the samples of different compositions $x \mathrm{Li}_{2} \mathrm{MnO}_{3} \cdot(1-x) \mathrm{LiM}_{1 / 3} \mathrm{Ni}_{1 / 3} \mathrm{Co}_{1 / 3} \mathrm{O}_{2}(x=0.2-0.5)$, the sample LMR35, containing $35 \mathrm{~mol} \%$ of $\mathrm{Li}_{2} \mathrm{MnO}_{3}$, shows better electrochemical characteristics and differs from other samples by much higher $\mathrm{Li}^{+}$diffusion coefficient and possibly contains fewer structural defects.

\section{ACKNOWLEDGEMENTS}

The work was supported by the Russian Science Foundation, Grant \# 17-13-01424.

\section{REFERENCES}

[1] THACKERAY, M. M., JOHNSON, C. S., VAUGHEY, J. T., Li, N., and HACKNEY, S. A. Advances in manganeseoxide 'composite' electrodes for lithium-ion batteries. J. Mater. Chem. 2005. vol. 15, pp. 2257-2267.

[2] CHOI, N.-S., CHEN, Z., FREUNBERGER, S. A., JI, X., SUN, Y.-K., AMINE, K., YUSHIN, G., NAZAR, L. F., CHO, J., and BRUCE, P. G. Challenges Facing Lithium Batteries and Electrical Double-Layer Capacitors. Angew. Chem. Int. Ed. 2012. vol. 51, pp. 9994-10024.

[3] ERICKSON, E. M., SCHIPPER, F., PENKI, T. R., ERK, C., SHIN, J.-Y., CHESNEAU, F. F., MARKOVSKY, and B., AURBACH, D. Review-Recent Advances and Remaining Challenges for Lithium Ion Battery Cathodes. J. Electrochem. Soc. 2017. vol. 51, pp. A6341-6348.

[4] KALYANI, P., CHITRA, S., MOHAN, T., and GOPUKUMAR, S. Lithium metal rechargeable cells using $\mathrm{Li}_{2} \mathrm{MnO}_{3}$ as the positive electrode. J. Power Sources. 1999. vol. 80, pp. 103-106.

[5] THACKERAY, M. M., KANG, S. H., JOHNSON, C. S., VAUGHEY, J. T., BENEDEK, R., and HACKNEY, S. A. $\mathrm{Li}_{2} \mathrm{MnO}_{3}$-stabilized $\mathrm{LiMO}_{2}(\mathrm{M}=\mathrm{Mn}, \mathrm{Ni}$, Co) electrodes for lithium-ion batteries. J. Mater. Chem. 2007. vol. 17, pp. 3112-3125.

[6] SATHIYA, M., ROUSSE G., RAMESHA K., LAISA C. P., VEZIN H., SOUGRATI M. T., DOUBLET M.-L., FOIX D., GONBEAU D., WALKER W., PRAKASH A. S., BEN HASSINE M., DUPONT L., and TARASCON J.-M.

Reversible anionic redox chemistry in high-capacity layered-oxide electrodes. Nature Mater. 2013. vol. 12, pp. 827-835.

[7] McCALlA E., ABAKUMOV A. M., SAUBANERE M., FOIX D., BERG E. J., ROUSSE G., DOUBLET M.-L., GONBEAU D., NOVAK P., VAN TENDELOO G., DOMINKO R., and TARASCON J.-M. Visualization of O-O peroxo-like dimers in high-capacity layered oxides for Li-ion batteries. Science. 2015. vol. 350, pp. 1516-1521.

[8] ASSAT G., FOIX D., DELACOURT C., IADECOLA A., DEDRYVERE R., and TARASCON J.-M. Decoupling Cationic-Anionic Redox Processes in a Model Li-Rich Cathode via Operando X-ray Absorption Spectroscopy. Chem. Mater. 2017. vol. 29, pp. 9714-9724.

[9] LU, Z., MACNEIL, D. D., and DAHN, J. D. Layered Cathode Materials Li[Nix $\mathrm{Li}_{(1 / 3-2 \times / 3)} \mathrm{Mn}_{(2 / 3-x / 3)} \mathrm{O}_{2}$ for Lithium-lon Batteries. Electrochem. Solid-State Lett. 2001. vol. 4, pp. A191-A194. 
[10] CROY J. R., BALASUBRAMANIAN M., GALLAGHER K. G., and BURRELL A. K. Review of the U.S. Department of Energy's "Deep Dive" Effort to Understand Voltage Fade in Li- and Mn-Rich Cathodes. Acc. Chem. Res. 2015. vol. 48, pp. 2813-2821.

[11] MAKHONINA E.V., MASLENNIKOVA L.S., VOLKOV V.V., MEDVEDEVA A.E., RUMYANTSEV A.M., KOSHTYAL YU.M., MAXIMOV M. YU., PERVOV V.S., and EREMENKO I.L. Li-rich and Ni-rich transition metal oxides: Coating and core-shell structures. Appl. Surf. Sci. 2019. vol. 474, pp. 25-33.

[12] BOULINEAU A., CROGUENNEC L., DELMAS C., and WEILL F. Structure of $\mathrm{Li}_{2} \mathrm{MnO}_{3}$ with different degrees of defects. Solid State Ionics. 2010. vol. 180, pp. 1652-1659.

[13] IVANISHCHEV A.V., CHURIKOV A.V., USHAKOV A.V. Lithium transport processes in electrodes on the basis of $\mathrm{Li}_{3} \mathrm{~V}_{2}\left(\mathrm{PO}_{4}\right)_{3}$ by constant current chronopotentiometry, cyclic voltammetry, and pulse chronoamperometry. Electrochim. Acta. 2014. vol. 122, pp. 187-196.

[14] MOHANTY Debasish, HUQ Ashfia, PAYZANT E. Andrew, SEFAT Athena S., Li Jianlin, ABRAHAM Daniel P., WOOD David L., and DANIEL Claus. Neutron Diffraction and Magnetic Susceptibility Studies on a High-Voltage

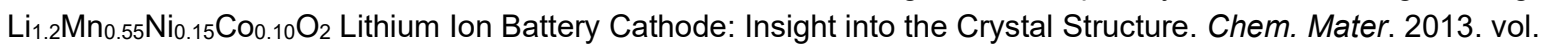
25, pp. 4064.

[15] CHERNOVA NATASHA A., MA MIAOMIAO, XIAO JIE, WHITTINGHAM M. STANLEY, BREGER JULIEN, AND GREY CLARE P. Layered LixNiy Mny $\mathrm{C}_{1-2 y} \mathrm{O}_{2}$ Cathodes for Lithium lon Batteries: Understanding Local Structure via Magnetic Properties. Chem. Mater. 2007. vol. 19, pp. 4682-4693. 